\title{
O DISPOSITIVO DA CRIMINALIDADE E SUAS ESTRATÉGIAS ${ }^{\star}$
}

\author{
Gilead Marchezi Tavares ${ }^{\star}$
}

\begin{abstract}
RESUMO
Trata-se de ensaio sobre como são produzidas, no contexto em que vivemos, subjetividades criminosas. Partindo da ideia de "dispositivo da criminalidade", propõe-se como estratégias de tal diagrama de forças do contemporâneo o medo/acuamento, a desconfiança/desfiliação e a violência/ausência de sentido para a ação. Os efeitos do dispositivo da criminalidade são, por um lado, subjetividades engajadas na crença de identidades/essências de gente inferior e gente de verdade; por outro, discursos sobre segurança pública e situação de risco. Acredita-se que os mecanismos que põem em funcionamento o dispositivo da criminalidade integram prisões, projetos sociais para a infância empobrecida, políticas públicas, etc.
\end{abstract}

Palavras-chave: criminalidade; prisões; situação de risco; subjetividade.

\section{THE CRIMINALITY DEVICE AND ITS STRATEGIES}

\begin{abstract}
This essay discusses how criminal subjectivities are produced within the context where we live. Strategies of this contemporary force diagram are proposed, stemming from the idea of "criminality device", such as fear/cornering, mistrust/disassociation, and violence/nonexistence of meaning for action. The effects of the criminality dispositive are, on one hand, subjectivities engaged on the belief of identities/essences of inferior people and true people; and on the other hand on discourses about public safety and risk situation. The mechanisms that influence the criminality dispositive integrate prisons, social projects for poor children, public policy, etc.
\end{abstract}

Keywords: criminality; prisons; risk situations; subjectivity.

^ Texto apresentado no Seminário de Ciências Criminais, na Mesa com o tema "Criminologia e Subjetividade no Brasil", que ocorreu de 28 a 30 de abril de 2009 no Centro de Ciências Jurídicas e Econômicas da Universidade Federal do Espírito Santo/Vitória. Fonte de financiamento: Programa de Educação Tutorial - MEC

$\star \star$ Psicóloga. Doutora em Psicologia pela Universidade Federal do Espírito Santo. Atualmente é Professora Adjunta do Departamento de Psicologia e do Programa de Pós-Graduação em Psicologia Institucional da Universidade Federal do Espírito Santo. Endereço: Universidade Federal do Espírito Santo. Av. Fernando Ferrari. Goiabeiras. Vitoria, ES - Brasil. CEP: 29000-000.

E-mail: gilead.dindin@ig.com.br 


\section{Apresentação}

O que pretendo apresentar é um ensaio, baseado no referencial foucaultiano, sobre os processos de subjetivação que atualizam formas criminosas, ou dito de outra maneira, arrisco uma análise de como são produzidas, no contexto em que vivemos, subjetividades criminosas. A subjetividade é aqui entendida como formas de ser, estar e sentir que não se encontram dentro do sujeito como uma essência, por exemplo, ou como verdade interior da pessoa, mas que compõem os sujeitos por atravessamentos, por isso a expressão "processos de subjetivação".

Rauter (2007) apresenta a ideia de "dispositivo da criminalidade" como diagrama de forças que se atualiza por desdobramento nas instituições carcerárias e afirma que tal dispositivo é uma das principais ferramentas de controle social no mundo globalitário. Seguindo o pensamento da autora, acredito que a subjetividade criminosa é a outra face da subjetividade encarcerada, que não necessariamente tem como cenário o interior da prisão. Se a prisão é um sintoma da questão da criminalidade (YOUNG, 2003) - e não a sua solução, como seria óbvio pensar - e, por isso, pode ser entendida como componente da grande engrenagem que produz subjetividades criminosas (dispositivo da criminalidade), que outros componentes tal diagrama de forças comporta? Como outras instituições entram neste jogo de forças?

Deleuze (1988), apresentando as principais ideias de Foucault, aborda o diagrama como dimensão informe que se configura como mapa, relevo ou cartografia das relações de poder co-extensivas a todo o campo social. Nesse sentido, as relações de poder devem ser ponto de partida para a análise das instituições e não o contrário. Partindo de tais considerações, impõe-se como questão para as discussões que pretendo trazer: quais as estratégias das relações de poder contemporâneas? Tal pergunta implica ainda em sondar qual é o alvo do poder hoje, quais os seus dispositivos (agenciamentos concretos e/ou abstratos), que função política imediata opera e que efeitos encerra?

\section{Perigo e risco na sociedade de controle}

A proposição de análise se inicia pela consideração da disseminação da noção de risco e sua especial utilização nos dias atuais pelas políticas públicas de modo geral. É notável como o objetivo e o alvo de diversas políticas públicas hoje tem sido a abordagem às pessoas "em risco", "de risco" e "em situação de risco". Tal discurso tem atingido políticas públicas de ação social, de educação, de segurança urbana e de saúde. Mesmo que a utilização da noção não seja unívoca nas diversas políticas referidas, o risco pode ser pensado como analisador das subjetividades contemporâneas (cf. SPINK, 2000).

A análise da disseminação da ideia do risco social e pessoal prescinde de uma retomada de processos históricos relativos ao poder, que foram muito discutidos pelo filósofo Michel Foucault. Dessa forma, podemos relembrar que a partir do séc. XVII, com a consolidação dos Estados-Nação, observa-se que outra lógica de relação se opera no tecido social. Foucault (1989) descreve a relação 
de forças de tal conjuntura como poder disciplinar. Este se diferenciava da lógica da relação de forças do feudalismo, a qual o autor denominou de poder soberano, cujo objetivo parecia estar no desinvestimento da vida. Nas palavras de Lavrador (2004, p. 121): “[...] não é sobre a vida que esse poder age, ou melhor, a ação que se dá sobre a vida é a de matar", o que recebeu de Foucault (2002) a insígnia de "fazer morrer e deixar viver". O poder disciplinar, que se configura com o advento das indústrias, por outro lado, promove uma economia anátomopolítica das forças, que investe o corpo dos indivíduos de modo a torná-los úteis e dóceis ao capital em plena ascensão. É a partir desse sentido que, em Vigiar e Punir, Foucault (1989) utiliza a instituição prisão como dispositivo para analisar o poder disciplinar. Suas estratégias são descritas na obra como o exame, a fila, a repetição, a vigilância etc. A prisão e, por conseguinte, o delinquente são efeitos do poder disciplinar, são produzidos nas práticas sociais que operam a partir de tal poder, assim como a fábrica e o operário, a escola e o aluno etc.

Foucault (1996) usa o termo "perigoso" como analisador da sociedade caracterizada pelo poder disciplinar, enquanto condição de possibilidade da emergência da norma, que é o próprio fundamento relacional da disciplina. O perigo, portanto, habitava o sentido do incontrolável, do imprevisível, "das virtualidades". A noção de periculosidade

[...] significa que o indivíduo deve ser considerado pela sociedade ao nível de suas virtualidades e não ao nível de seus atos; não ao nível das infrações efetivas a uma lei efetiva, mas das virtualidades de comportamento que elas representam (Foucault, 1996, p. 85).

A norma, que tem como pilares o exame e a vigilância, emerge como balizadora do incontrolável e do imprevisível,

[...] um efeito fundamental das sociedades disciplinares é que por suas instituições a categoria de "homem civilizado" torna-se o modelo de homem do mundo... Esse modelo e suas normas correlatas ultrapassam as fronteiras das instituições e começam a se tornar objeto de lei. Inauguram-se, assim, as sociedades de normatização, nas quais os valores da norma são tornados referenciais para os valores da moral, da justiça, do trabalho, da penalidade, enfim, para toda a sociedade (MORAES; NASCIMENTO, 2002, p. 93).

Acontece ainda que, na passagem do século XVIII para o XIX, novos elementos passam a compor o jogo de forças, conforme Foucault (2004). Primeiramente pelo deslocamento do foco no que se refere à gestão dos perigosos, ou seja, a psiquiatria e, por consequência, o direito punitivo, passam a se ocupar dos criminosos, e não tanto do crime; do perigo potencial, e não tanto do ato cometido; da proteção da sociedade, não somente da punição do criminoso; o que promove a intervenção pela prevenção e não somente pelo tratamento. Depois, a partir da segunda metade do século XIX, a noção de risco é consolidada pela 
Economia e pela Medicina (SPINK; MEDRADO; MELLO, 2002), diferentemente do que se via até então. Se antes a ideia de "risco" estava intimamente relacionada aos "jogos de azar", agora ela comparece como algo que pode ser gerenciado. Desse modo, desloca-se o perigo da ordem do imponderável, de modo a colocá-lo numa escala de previsibilidade, dividindo-o o máximo possível e esquadrinhando-o em suas frações recônditas até torná-lo passível de controle, isto é, arrebanhá-lo dentro dos limites dos "riscos".

A noção de perigo/risco aciona a formação de uma série de instituições de sequestro que têm como finalidade fixar os indivíduos sob um controle que se pode exercer por meio da prevenção e da exclusão. Tais instituições apresentam como estratégias do poder a vigilância permanente sobre os indivíduos e como um dos efeitos o saber sobre os indivíduos: "um saber que tem por característica [...] determinar se um indivíduo se conduz ou não como deve, conforme ou não à regra, se progride ou não etc." (FOUCAULT, 1996, p. 88). É nesse contexto que as práticas preventivas associam-se à vigilância do que ou de quem comporta em si a periculosidade.

O século XIX traz a incorporação da cidade e da população no campo do saber médico pela política de higienização da sociedade e de seus espaços públicos. Através do discurso médico e das noções de puericultura por ele introduzidas, passa-se a intervir na família para a formação de um novo modelo de família: a família higiênica, intimista e privativa, em suma, a família moderna (BULCÃO, 2002).

Dessa forma, no Brasil, chegamos ao século XX com a "Missão Patriótica" da elite científica de instauração de uma Nação Moderna a partir do saneamento moral do país. Tal missão se atualiza por meio das Políticas de Assistência Social. Estas têm nos projetos sociais de atendimento à infância empobrecida seu principal expoente. Coimbra e Nascimento (2005) nos auxiliam na compreensão de que a pobreza é percebida e tratada na sociedade moderna como possuidora de uma "moral duvidosa", transmitida hereditariamente, pertencente a uma classe "mais vulnerável" aos vícios e às doenças. Seus filhos devem ser afastados dos ambientes perniciosos, como as ruas. Assim, os pobres, considerados "viciosos", são portadores de delinquência, são libertinos, maus pais e vadios, representando um perigo social que deve ser erradicado.

Indo além na análise do jogo de forças, Foucault (2002) apresenta como diagrama do poder operante no tecido social moderno o "biopoder". Este é exercido através de uma tecnologia de dupla face: disciplinar, que se dirige ao homem-corpo, e biopolítico, que mobiliza a gestão da vida, dirigindo-se à população como um todo, ao homem-espécie. O biopoder operacionaliza uma incidência que se caracteriza por uma organização rizomática e por uma ação disseminada nos mais ínfimos detalhes da vida, revestindo-a de ponta a ponta (PELBART, 2003) e regulamentando um direito que deverá "fazer viver e deixar morrer". Aqui "[...] o poder tomou posse da vida. Ele vai do indivíduo à população, do corpo à espécie, do privado às cidades" (LAVRADOR, 2004, p. 122). Dessa forma, ao falar de biopoder, Foucault (2002) descreve técnicas 
de regulamentação da vida, diferenciando a população que deve ser protegida daquela que deverá ser combatida em nome da defesa da sociedade. A partir da ascensão dos mecanismos de controle da vida das populações, a concordância com a eliminação ou exclusão de determinada categoria de pessoas baseia-se na premissa de que tais sujeitos oferecem perigo às vidas eleitas como superiores. A partir de Foucault (2002) apreendemos, neste contexto, a política da sociedade moderna, que reverte a ótica do poder do soberano, do "fazer morrer e deixar viver" em "fazer viver e deixar morrer". Desse mapeamento dos pobres surge uma grande preocupação com a infância e a juventude que poderão compor as "classes perigosas". Como se vê, as crianças e os jovens "em perigo/risco" devem ter suas virtualidades controladas permanentemente.

Entendemos ainda, em conjunto com Deleuze (1992), que podemos compreender a sociedade contemporânea como mobilizada por ações/relações que forjam subjetividades engajadas no sofrimento (que seja, pelo esmagamento da própria subjetividade em função de sua efemeridade), o que seria uma estratégia política da "sociedade de controle". A sociedade de controle seria marcada pela interpenetração dos espaços, por sua suposta ausência de limites definidos (a rede) e pela instauração de um tempo contínuo no qual os indivíduos nunca conseguiriam terminar coisa alguma, pois estariam sempre enredados numa espécie de formação permanente, de dívida impagável, prisioneiros em campo aberto. $\mathrm{O}$ que haveria aqui, segundo Deleuze (1992), seria uma espécie de modulação constante e universal que atravessaria e regularia as malhas do tecido social.

Parece ser nesse sentido que a sociedade de controle poderia ter mais um complemento: sociedade de controle "de riscos".

\section{Trazendo nOVOS COMPONENTES PARA A ANÁlise do DiAgRAMA ATUAL: O MEDO, A DESCONFIANÇA E A VIOLÊNCIA}

Retomando o dispositivo da criminalidade proposto por Rauter (2007, p. 42), consideremos “[...] como fazendo parte desse dispositivo o medo à criminalidade que se espalha nas cidades, as demandas punitivas produzidas através de discursos de lei e ordem disseminados pela mídia, os efeitos subjetivos dessas campanhas [...]". A sensação de medo parece ser parte constituinte dos modos de vida contemporâneos. Não é para menos que a segurança pública é o tema principal de discussão em muitas partes do mundo, segundo Wacquant (2001). Entre os grandes temas sociais, a segurança pública é o mais discutido ou mais abordado hoje também no Brasil. Em várias capitais, o problema da criminalidade relacionada ao tráfico de drogas parece ter tomado de vez a cena. Nas campanhas para sucessão presidencial, ocorridas nos anos de 2002, 2006 e 2010, o plano mais requisitado pelos eleitores, repórteres e opositores foi o da intervenção programada para o combate à criminalidade. Notável, ainda que requentada, foi a presença da ideia de endurecimento contra o crime com medidas de segurança que vão desde um aparato policial vigoroso a um sistema punitivo impiedoso, tanto por parte de programas de governo como por parte da opinião pública. 
Wacquant (2001) nos faz pensar que o sentimento de insegurança e o foco da atenção voltado primordialmente para a violência, como sinônimo de criminalidade, são fenômenos mundiais ampliados pelo processo neoliberal de globalização da economia:

A penalidade neoliberal apresenta o seguinte paradoxo: pretende remediar com um "mais Estado" policial e penitenciário o "menos Estado" econômico e social que é a própria causa [grifo do autor] da escalada generalizada da insegurança objetiva e subjetiva em todos os países, tanto do Primeiro como do Segundo Mundo (WACQUANT, 2001, p. 07).

Vê-se a perversão da penalidade neoliberal, segundo o autor, quando aplicada a países com grande desigualdade de condições e de oportunidades, sem tradição democrática e, no caso brasileiro em particular, com uma concepção hierárquica de cidadania - em que todos são iguais, mas uns são mais "iguais" que outros - que faz confundir a manutenção da ordem pública com a manutenção da ordem de classe. Nesse sentido, o investimento no Estado Penal com a intensificação da intervenção do aparelho policial e judiciário é o mesmo que implantar uma verdadeira ditadura sobre os pobres.

O medo e a sensação de insegurança se prestam não somente para práticas de apartheid no tecido social, ou seja, para separar os que merecem viver daqueles que podem morrer em nome da defesa da sociedade, mas também para “[...] a produção de apatia e o desânimo indo até o surgimento de múltiplas patologias que irão levar à utilização de medicação psiquiátrica, patologias somáticas, etc." (RAUTER, 2007, p. 42). O medo e a insegurança colocam os sujeitos em lugar de acuamento. Acuados, os sujeitos não apostam nada, nada arriscam, tornandose inertes ou reativos. Neste último caso, atualizando a moral do ressentimento, a partir de Nietzsche (1998), apostam tudo porque "não há nada mais a perder". Pensando o medo como estratégico para o dispositivo do jogo de forças operantes no atual momento sócio-histórico, o apresentamos como um disparador das condições de possibilidade, isto é, das alternativas abertas no campo como resultado das relações de força que definem as opções de emergência em relação aos processos de subjetivação. Desse modo, tal componente configura-se como parte da estratégia utilizada pelo poder no contemporâneo.

Temos ainda as campanhas policiais, com cartilhas e palestras, os alertas nas agências bancárias e as notícias jornalísticas de estelionato com o uso da má fé que demonstram que não se pode confiar em ninguém. Assim, a desconfiança, mais um elemento presente nos estabelecimentos carcerários, pode ser colocado em análise como componente de uma engrenagem que extrapola tal campo institucional. Medo e desconfiança parecem se imbricar passando a ocupar sentidos próximos ou paralelos na medida em que compõem um mesmo diagrama de forças. 
Nas relações prisionais, a desconfiança geral entre os detentos é marcante. Acreditamos que o Sistema Prisional produz tal relação de desconfiança, primeiro quando pune a todos de forma cruel pelo erro de um, segundo quando, de certa forma, chantageia os mais fracos ou inseguros de modo a forçá-los a alcaguetar. A desconfiança produz instabilidade no presídio. A instabilidade justifica providências drásticas dos diretores e violência da polícia de elite, além de reproduzir o estereótipo de periculosidade de presos. A desconfiança pode ser pontuada pela fala de preso documentada em Souza (1976, p. 78): "A prisão é um centro de perda de confiança. A gente, aqui, tem que ter uma resposta para uma pergunta que não foi feita e um álibi para uma situação que ainda não foi criada".

A desconfiança faz parte da vida intramuros, reproduzindo as relações de poder e impedindo a construção e o desenvolvimento de movimentos sociais que culminem na transformação do sistema prisional (TAVARES, 2001). Dessa forma, a que se presta a desconfiança? Produção de solidão e desfiliação - segundo Castel (1998), relações sociais desprovidas de sentido, de projeto e de consistência - por um lado, e por outro, engajada no ressentimento, se presta ao uso da "má fé", para a conquista da confiança alheia no intuito de golpe, "de lhe passar a perna".

$\mathrm{O}$ que se pretende aqui argumentar é que o grande espetáculo em torno de questões de segurança pública, envolvendo a utilização maciça do aparato policial, a construção de presídios de segurança máxima, os holofotes da grande mídia etc., tem como efeitos primeiros medo e insegurança. Os processos de subjetivação engendrados no espetáculo em torno de questões de segurança pública, atravessados assim pelo medo e pela insegurança, apontam cada vez mais para produção de subjetividades criminosas.

Um terceiro elemento coloca-se ainda no jogo de forças e parece ser o mais óbvio em nosso contexto (dada a sua banalização no cotidiano e ao mesmo tempo ao seu efeito de horror entre as pessoas): as manifestações e dramatizações de violência. Giram em torno desta questão todos os grandes problemas sociais, de modo que a violência sinaliza um atravessamento geral da rede social. Não é por menos que se percebe a violência como presente em todas as esferas das interações sociais: no trânsito, nas relações afetivas, na escola, no esporte etc. Instrumento para resolução de conflitos, ação em nome de reconhecimento social, meio para aquisição de bens, ou, como pensam alguns, simplesmente "de graça", a violência aparece também como cena tragicômica no cotidiano. Assim, as pessoas relatam situações de violência dramatizando-as, destacando momentos mais chocantes, e os expectadores parecem se deleitar com a narrativa. Basta ler as páginas policiais de boa parte dos jornais que circulam nas cidades. Dessa forma, a violência parece cumprir a função de esvaziamento de sentido dos afetos que compõem o jogo de forças. Num entendimento extremado, seria como se a distância subjetiva entre os sujeitos envolvidos na cena fosse de tal ordem que simplesmente não há sentido a habitar. 
Depoimentos de internos de presídio capixaba em relação às situações marcantes vividas em prisões, relatados por Tavares (2006), auxiliam no entendimento das manifestações da violência como esvaziamento de sentido dos afetos constituintes das relações e, como consequência, a dramatização da violência como busca de sentido no nonsense do sofrimento.

[...] Deu um monte de facadas aqui assim e quando eu cheguei lá encontrei os caras limpando, arrancando o olho, o dente [...] Ficou só o buraco assim e eles estavam pegando o olho dele na mão, os dentes. Ficou só o cérebro mesmo e isso me surpreendeu. Eu gostava dele, era um cara bom. Eu fiquei sem dormir, fiquei com medo [...] (Fala de interno do sistema penitenciário capixaba, Jader, 26 anos, extraída de TAVARES, 2006, p. 104).

[...] Olhava aquela pessoa caída no chão, respirando, o sangue saindo pelo nariz, pela boca, ouvido. Aquilo me deixou muito triste, me deu uma angústia no coração, dava um frio na barriga, um negócio ruim demais, demais, demais" (Fala de interno do sistema penitenciário capixaba, Jessé, 29 anos, extraída de TAVARES, 2006, p. 103).

Vários sociólogos aproximaram o sentido da violência das ideias de medo e de desconfiança, e o fizeram tomando como ponto de giro o conceito de exclusão social. O termo exclusão se prestou à ampliação do conceito de pobreza, através de Atkinson (1998); à compreensão da perda da identidade de trabalhador a partir da crise da sociedade salarial, através de Castel (1998); ao entendimento das dificuldades de viver de determinados grupos limitados a um espaço urbano de baixo calão social, através de Bourdieu (1997); deu luz à desigualdade social presente nas relações sociais, através de Santos (2001); significou um rótulo marcante da divisão de dois mundos, o dos incluídos e o dos excluídos, denunciado por Martins (1997) como um equívoco que retrata imperfeitamente processos de inclusão marginal; refletiu a face econômica do neoliberalismo globalizado de culpabilização popular e a segregação e o confinamento que produzem verdadeiro apartheid entre classes sociais. Tais sentidos culminam com a proximidade da exclusão social com a violência e o sentimento de insegurança, pois os contingentes populacionais entendidos como "excluídos" gerariam um sentimento de hostilidade, desconfiança e medo por parte dos demais setores da sociedade. A exclusão social pode ser analisada como distanciamento subjetivo entre sujeitos que têm medo e desconfiança quanto a todo o mundo. Tais sujeitos não buscam "bons encontros", no sentido utilizado por Espinosa (1983[1677]), não constroem relações afetivas de proximidade, que sinalizariam para um sentimento de felicidade pública de composição com outros. O efeito de distanciamento subjetivo foi apontado por Bauman (1999) como característico do movimento globalitário. Este eliminou grandes distâncias geográficas, substituindo-as por grandes distâncias afetivas. 


\section{A título de ConClusão}

O medo/acuamento, a desconfiança/desfiliação e a violência/inexistência de sentido, como estratégias do "dispositivo da criminalidade", produzem subjetividades engajadas no sofrimento psíquico ou no esmagamento do sentido subjetivo/afetivo. Acreditamos que é apenas numa sociedade que tem como característica a individualização reflexiva (cf. BECK, 1993) que se faz pertinente a análise de tal dispositivo. A distância subjetiva representa um tipo de niilismo passivo, como propõe Nietzsche (1978), em que a dormência dos sentidos preenche a desencarnação das pessoas de sua própria vida. As pessoas, assim, parecem "passar" pelo mundo como turistas, surpreendendo-se passageiramente com tudo o que veem, mas logo mudando a atenção para outros chamarizes. A desencarnação só cede lugar ao sofrimento da desfiliação. Não à toa observamos um sentimento exagerado de sofrimento das pessoas em geral, tendo como indicativo, por exemplo, o aumento do uso de psicotrópicos. O sofrimento, digo isto lembrando as reservas e o cuidado em elaborar tal análise, parece também estar banalizado: todo mundo sofre muito e às vezes exageradamente.

Exemplificando as reservas quanto ao exagero do sofrimento e aproveitando para ilustrar a análise proposta, lembro o trabalho de Tavares (2006) em que entrevistou internos de penitenciária estadual capixaba e cujo corpus de análise apontou para o encarceramento como "sofrimento", termo utilizado de forma geral por todos os 16 entrevistados ao darem sentido à prisão.

Em outro trabalho, Tavares et al. (2009), investigando projeto social que atende crianças e adolescentes em situação de risco social, narram uma situação que vivenciaram em ônibus no trajeto para o trabalho de campo:

O cobrador do ônibus remete-se a nós e afirma reticente:

_ Vocês não são daqui...

_ Não. Por quê? - Perguntamos.

_ Vocês são gente - Responde o cobrador, deixando-nos estupefatas.

Para as autoras, os projetos sociais, que objetivam proteger a vida de crianças e adolescentes dos riscos presentes no mundo da rua, atualizam subjetividades engajadas no sofrimento de ser "apêndice social", na medida em que a criança pobre atendida pelos projetos "precisa aprender a ser gente" e aprende isso se reconhecendo como gente inferior que necessita de salvamento.

Desse modo, concluem as autoras, os projetos sociais, fomentados pelas políticas públicas de atenção à infância - educacionais, assistenciais etc. - como dispositivos da sociedade contemporânea, operam integrações sobre substâncias qualificadas (crianças e adolescentes empobrecidos) e funções finalizadas (edu- 
cação, disciplina, proteção) para produzir forma de conteúdo definível, visível: o "menino do projeto", sobre a qual se é possível falar: "discurso sobre o risco social e pessoal". O "menino do projeto" está no limite, nem se é menino de rua, pivete, nem se é criança educada, bem-criada e de bons modos. Ficando-se assim no meio do caminho, no limiar entre um e outro, acaba por denunciar suas virtualidades, como sua "provável" "natureza perigosa", solicitante ao mesmo tempo de vigilância e de proteção.

Os mecanismos que põem em funcionamento a grande engrenagem, o "dispositivo da criminalidade", integram agenciamentos de naturezas diversas, tais como, as prisões e os projetos sociais, por um lado, e as políticas públicas, por outro, que juntos operam um controle social amplificado, envolvendo as prevenções e o gerenciamento das virtualidades dos perigosos, produzindo inclusive as identidades/essências de ser humano, de bandidos, de gente inferior, de "elementos", de meninos de projeto etc.

Dessa forma, ao que tudo indica, projetos sociais, abrigos, estabelecimentos para adolescentes em conflito com a lei, direcionados ainda pelas políticas públicas de assistência social e de atenção à infância empobrecida, parecem não estar caminhando para a transformação da realidade social e sim no intuito de localizar, separar e identificar aqueles que passarão a ser chamados de pessoas de risco/perigosos. Assim também, as prisões são claramente ineficientes no papel de recuperação dos apenados, mas continuam a existir por cumprirem a função política de localização, segregação e identificação daqueles que "podem morrer" e de composição do dispositivo da criminalidade, por meio da disseminação do medo, da desconfiança e da violência. A instituição prisão não se refere aos muros que circunscrevem o estabelecimento penal. Ela fala de ações/relações presentes no contexto em que se crê existirem "coisas desse mundo" a se temer (alusão à Glassner (2003), sobre os medos existentes em diferentes momentos históricos), de modo a se operar permanentemente divisões entre os confiáveis e os não confiáveis, mantendo uma linha tênue entre eles (já que se poderá passar de um lado ao outro em razão dos riscos produzidos constantemente). Os efeitos de tal conjunto de práticas e de concepções são a crença na resolução dos conflitos pelo armamento, na eliminação do "mal", na binarização dos elementos constituintes no mundo em bom $X$ mau e bem $X$ mal.

A produção de subjetividades criminosas é a função política do dispositivo da criminalidade (operado pela prisão, por projetos sociais, por abrigos, por unidades de internação para jovens, por políticas públicas, pelos sistemas de segurança, etc.), que tem como estratégias de efetuação o medo, a desconfiança e a violência. Enquanto isso, parece que não estamos dispostos a mudar o rumo, clamando cada vez mais por segurança penal em vez de social.

A incapacidade brasileira de enfrentar a violência urbana tem o mesmo fundamento da americana: qualquer mudança em sociedades tão desigual é vista e sentida com pavor. E continuamos a investir nosso medo nos alvos mais improváveis, a dissimular o que efetivamente nos inquieta (PINHEIRO, 2003, p. 18). 


\section{REFERÊNCIAS}

ATKINSON, R. Combatendo a exclusão social urbana: o papel da participação comunitária na regeneração das cidades européias. Cadernos IPPUR - Instituto de Pesquisa e Planejamento Urbano e Regional da UFRJ. Rio de Janeiro, ano XII, n. 01, p. 107-128, 1998.

BAUMAN, Z. Globalização: as conseqüências humanas. Rio de Janeiro: J. Zahar, 1999.

BECK, U. Risk society: towards a new modernity. London: Sage, 1993.

BOURDIEU, P. A miséria do mundo. Petrópolis: Vozes, 1997.

BULCÃO, I. A produção de Infâncias desiguais: uma viagem na gênese dos conceitos "criança" e "menor". In: NASCIMENTO, M. L. (Org.). PIVETES: a produção de infâncias desiguais. Niterói: Intertexto; Rio de Janeiro: Oficina do Autor, 2002, p. 61-73.

CASTEL, R. As metamorfoses da questão social: uma crônica do salário. Petrópolis: Vozes, 1998.

COIMBRA, C. M. B.; NASCIMENTO, M. L. Ser jovem, ser pobre é ser perigoso? JOVENes, Revista de Estudios sobre Juventud. México, v. 9, n. 22, p. 338-355, 2005.

DELEUZE, G. Conversações. Rio de Janeiro: Ed. 34, 1992.

DELEUZE, G. Foucault. São Paulo: Brasiliense, 1988.

ESPINOSA, B. Ética demonstrada à maneira dos geômetras (1677). São Paulo: Abril Cultural, 1983.

FOUCAULT, M. A verdade e as formas jurídicas. Rio de Janeiro: Nau, 1996.

FOUCAULT, M. Ética, sexualidade, política. Rio de janeiro: Forense, 2004. Coleção Ditos e Escritos, v. 5.

FOUCAULT, M. Em defesa da sociedade. São Paulo: Martins Fontes, 2002.

FOUCAULT, M. Vigiar e Punir: história da violência nas prisões. Petrópolis: Vozes, 1989.

GLASSNER, B. Cultura do medo. São Paulo: Francis, 2003. 
LAVRADOR, M. C .C. Processos de exclusão e inclusão social. In: ABDALLA, M.; BARROS, M. E. B. (Org.). Mundo e sujeito: aspectos subjetivos da globalização. São Paulo: Paulus, 2004. p. 115-127.

MARTINS, J. S. Exclusão social e a nova desigualdade. São Paulo: Paulus, 1997.

MORAES, T. D.; NASCIMENTO, M. L. Da norma ao risco: transformações na produção de subjetividades contemporâneas. Psicologia em Estudo, Maringá, v. 7, n. 1, p. 91-102, 2002.

NIETZSCHE, F. Sobre o Niilismo e o Eterno Retorno (1881-1888). In: Obras incompletas. 2. ed. São Paulo: Abril Cultural, 1978. 416 p. Coleção Os Pensadores.

NIETZSCHE, F. Genealogia da moral: uma polêmica. São Paulo: Companhia das Letras, 1998.

PELBART, P. P. Vida capital: ensaios de biopolítica. São Paulo: Iluminuras, 2003.

PINHEIRO, P. S. Medo em todo lugar e em lugar nenhum. In: GLASSNER, B. Cultura do medo. São Paulo: Francis, 2003, p. 11-18.

RAUTER, C. Clínica e estratégias de resistência: perspectivas para o trabalho do psicólogo em prisões. Psicologia e Sociedade, Florianópolis, v. 19, n. 2, p. 42-47, 2007.1

SANTOS, B. S. Pela mão de Alice: o social e o político na pós-modernidade. São Paulo: Cortez, 2001.

SOUZA, P. A prisão. São Paulo: Alfa-Ômega, 1976.

SPINK, M. J. Contornos do risco na modernidade reflexiva: contribuições da psicologia social. Psicologia e Sociedade, Florianópolis , v. 12, n. 1/2, p. 156$173,2000$.

SPINK, M. J.; MEDRADO, B; MELLO, R. P. Perigo, probabilidade e oportunidade: a linguagem dos riscos na mídia. Psicologia: Reflexão e Crítica, Porto Alegre, v. 15, n. 1, p. 151-164, 2002.

TAVARES, G. M. Características e significados de rebeliões em prisões brasileiras: um estudo a partir de material jornalístico. Dissertação (Mestrado em Psicologia)-Programa de Pós-Graduação em Psicologia, Universidade Federal do Espírito Santo, Vitória, 2001. 
TAVARES, G. M. Trajetórias de vida de internos do sistema penitenciário capixaba: um estudo da rede de significações do processo de encarceramento a partir das práticas discursivas. 2006. 175 f. Tese (Doutorado)-Programa de Pós-Graduação em Psicologia, Universidade Federal do Espírito Santo, Vitória, 2006.

TAVARES, G. M. et al. A produção de meninos de projetos e acontecimentos no percurso. Relatório de Pesquisa. Departamento de Psicologia, Universidade Federal do Espírito Santo, Vitória, 2009. Mimeo.

WACQUANT, L. As prisões da miséria. Rio de Janeiro: J. Zahar, 2001.

YOUNG, J. A sociedade excludente. Rio de Janeiro: Revan, 2003.

Recebido em: setembro de 2009

Aceito em: fevereiro de 2011 